\title{
Computational prediction of Carica papaya extracts as potential drug agents against RNA polymerase and Spike proteins of SARS-nCoV2
}

Rashid Saif ( $\square$ rashid.saif37@gmail.com )

Gulab Devi Educational Complex, Lahore, Pakistan, 2. Decode Genomics, PUEHS (II), Lahore, Pakistan https://orcid.org/0000-0001-8915-242X

Muhammad Osama Zafar

Gulab Devi Educational Complex, Lahore, Pakistan

Muhammad Hassan Raza

Gulab Devi Educational Complex, Lahore, Pakistan

Talha Rehman

Gulab Devi Educational Complex, Lahore, Pakistan

\section{Saeeda Zia}

National University of Computer and Emerging Sciences, Lahore, Pakistan

Abdul Rasheed Qureshi

Gulab Devi Chest Hospital, Lahore, Pakistan

\section{Research Article}

Keywords: SARS-nCoV2, COVID-19, Carica papaya, spike protein, RdRP, RNA-dependent RNA polymerase, ligand-protein docking, computer-aided drug design, $\mathrm{MOE}$, molecular operating environment, lipinski's rule, molecular docking, novel coronavirus

Posted Date: November 11th, 2020

DOl: https://doi.org/10.21203/rs.3.rs-105301/v1

License: (c) (i) This work is licensed under a Creative Commons Attribution 4.0 International License. Read Full License 


\title{
Computational prediction of Carica papaya extracts as potential drug agents against RNA polymerase and Spike proteins of SARS-nCoV2
}

\author{
Rashid Saif ${ }^{1,2} *$, Muhammad Osama Zafar ${ }^{1}$, Muhammad Hassan Raza ${ }^{1}$, Talha Rehman ${ }^{1}$, Saeeda Zia $^{3}$, Abdul \\ Rasheed Qureshi ${ }^{4}$ \\ 1 Institute of Biotechnology, Gulab Devi Educational Complex, Lahore, Pakistan \\ 2 Decode Genomics, 323-D, Punjab University Employees Housing Scheme (II), Lahore, Pakistan \\ 3 Department of Sciences and Humanities, National University of Computer and Emerging Sciences, Lahore, \\ Pakistan \\ 4 Out Patient Department-Pulmonology, Gulab Devi Chest Hospital, Lahore, Pakistan
}

*Correspondence Author:

Dr. Rashid Saif

rashid.saif37@gmail.com

\begin{abstract}
The emergence of COVID-19 outbreak caused by SARS-nCoV2 (Severe Acute Respiratory Syndrome novel coronavirus 2), lead to the mass-scale mortalities around the world within a short span of time. The hour of the need is to develop the strategies and designing drugs/vaccines to control the spread of this contagion. In this paper, we predict the promising drug agents from the Carica papaya compounds by docking them with two major drug target proteins of SARS-nCoV2, spike (7BZ5) and RNA-dependent RNA polymerase (7BW4). For this purpose, we used Molecular Operating Environment Software (MOE) for ligand-protein interactions and docking scores. Furthermore, we used PubChem, PDB and SwissADME web portals to retrieve ligands structures, proteins structures and to check Lipinski's physiochemical parameters respectively. Cumulatively, this docking study has shown significant binding energies that $(-4.2034$ to $-8.9013 \mathrm{Kcal} / \mathrm{mol})$ indicates their potential against COVID-19 treatment. This study needs further evaluation on experimental basis.
\end{abstract}

Keywords: SARS-nCoV2; COVID-19; Carica papaya; spike protein; RdRP; RNA-dependent RNA polymerase; ligand-protein docking; computer-aided drug design; MOE; molecular operating environment; lipinski's rule; molecular docking; novel coronavirus 


\section{Introduction}

COVID-19 has been spreading around the globe in a vigorous manner since December 2019. Due to increase in confirmed cases and mortality rate worldwide, World Health Organization (WHO) declared the pandemic of novel coronavirus (SARS-nCoV2) as a global health emergency (Ahmed et al., 2020, Cucinotta and Vanelli, 2020, Hall Jr and Ji, 2020, Khaerunnisa et al., 2020, Kronbichler et al., 2020). This causative agent lead to the disturbance in respiratory tract and show symptoms like pneumonia that can damage various body organs in severe conditions (Prasanna and Abilash, 2020, Wang et al., 2020).

At present, no explicit remedies for COVID-19 are available, also the handling of this pandemic is deficient (Khaerunnisa et al., 2020). The researchers have identified major target proteins for drug designing which may be considered are: main protease/3C-like protease $\left(3 \mathrm{CL}^{\mathrm{pro}}\right)$, papain-like protease $\left(\mathrm{PL}^{\mathrm{pro}}\right)$, spike protein and polymerase protein RdRP (Bouchentouf and Missoum, 2020, Zhang et al., 2020, Mirza and Froeyen, 2020).

SARS-nCoV2 is an RNA virus having positive sense single strand of 27-32 kb approximately (Dhama et al., 2020, Khan et al., 2020). Due to its crown like appearance under electron microscope it is termed as CORONA (Pal et al., 2020). This virus is made up of different kind of structural proteins includes: Spike $(\mathrm{S})$, envelope $(\mathrm{E})$, membrane $(\mathrm{M})$ and nucleocapsid $(\mathrm{N})$ proteins, among them, $\mathrm{S}$ protein provides attachment site to host cell (Goswami et al., 2020, Li et al., 2003). ACE2; angiotensin-converting enzyme 2 is present on human cell membrane which work as receptor for SARS-nCoV2 (Wrobel et al., 2020). Spike protein significantly contributes the entry of virus into host cell which is concerned focus of therapeutic and vaccine design (Salvatori et al., 2020). The other target RNA-dependent RNA Polymerase is also considered to be the potent source for dealing with this disease. Coronaviruses assemble a multi RNA-synthesis complex of viral non-structural proteins (Nsps), which is accountable for transcription and replication of viral genome (Khan et al., 2020). Hence, the polymerase is a promising drug target (Peng et al., 2020). It infects the wide range of hosts including humans and other animals as well. Presumably, the transmission of this virus in humans is via droplets which come out of an infected person's mouth after sneezing or coughing along with direct contact (Khalid et al., 2020, Zou et al., 2020).

Different web-based or stationary based softwares were used for the computational analysis of drug designing. We used Molecular Operating Environment (MOE) software for molecular docking studies. It is a complete package which integrates ligand-protein docking, drug likeness attributes, molecular and binding interactions, modeling and simulations of structures and docking scores for interpreting the compatibility among the docked compounds (Santiago et al., 2008, Dar and Mir, 2017). Actively, our research is focused on the computational estimation of Carica papaya compounds having anti-inflammatory as well as immunomodulatory activities as a latent drug target, counter to SARS-nCoV2 RNA-Polymerase RdRP (7BW4) and Spike (7BZ5) protein. This study reassures scientists and pharmaceutical industries to have in-vitro and in-vivo investigations on those ligands for COVID-19 clinical trials. 
Figure 1 Comprehensive work stream of docking study

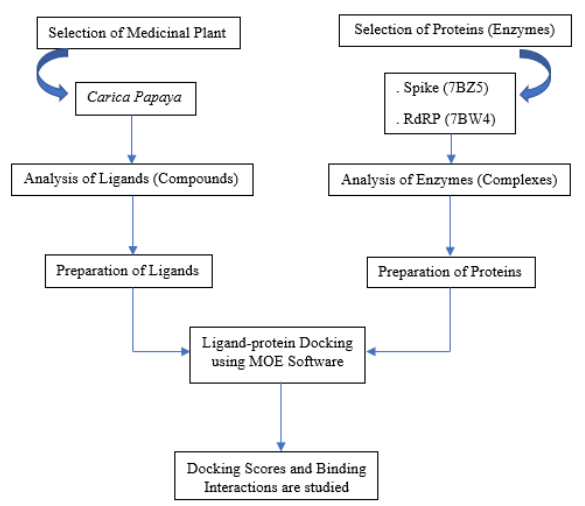

\section{Materials and method}

\subsection{Picking out the medicinal herb}

A lot of research is carried out on Carica papaya, commonly known as Papaya which is renowned for its medicinal properties among different regions of the world. It has potential for treating various ailments such as asthma, ulcer, diabetes and cardiovascular diseases (RiveraPastrana et al., 2010). Papaya extracts have significant immunostimulatory, antioxidant and inflammation reducing activities (Pandey et al., 2016). For these significances, scientists may consider papaya's derived substances for immunotherapeutic purposes against COVID-19 viral pandemic in near future under clinical tests.

\subsection{Preparation of ligands}

Firstly, by searching Carica papaya compounds from literature, we used chemical database (e.g. PubChem) to retrieve structures, and then using Molecular Operating Environment (MOE) software for preparation of ligands (Pandey et al., 2016). Table 2 reports the major chemical derived compounds of Carica Papaya collected. Furthermore, we downloaded Canonical Smiles of all associated ligands and exported one by one in MOE builder module to construct fully prepared ligands for molecular docking.

\subsection{Preparation of proteins (enzymes)}

Secondly, for major drug targets we selected two proteins of SARS-nCoV2 coronavirus having different nature (Wu et al., 2020, Wrobel et al., 2020). 3D structures of Spike S1 protein (https://www.rcsb.org/structure/7BZ5) and RNA-dependent RNA Polymerase (RdRP) (https://www.rcsb.org/structure/7BW4) are downloaded from Protein Data Bank (RCSB-PDB) under PDB ID of 7BZ5 and 7BW4 respectively. Crystallographic properties of 7BZ5 and 7BW4 are shown in Table 1. The structures of proteins are presented in Figure 2. We used open command to visualize these structures in MOE window and created the pure form of protein to make them ready for docking with the desired ligands. This step was carried out in the following ways. At first, we removed all the water molecules from the surface of protein and already 
attached inhibitors to avoid hinderance at interaction region while molecular docking for precise results. Secondly, we made structure preparation of selected proteins in MOE to resolve its chains error. After that, we found the active sites in Site Finder tab of MOE to create the space for attachment site for our ligands. As we were not familiar with the active site residues of an enzyme, we selected the longest chain from the list of possible catalytic sites, appeared on Site Finder window. In addition to, dummy sites were created by clicking on Dummies tab. Moreover, on completion of these steps our protein was fully prepared for docking.

Table 1 Crystallographic properties of proteins (enzymes)

\begin{tabular}{ccccccccc}
\hline Enzyme & $\begin{array}{c}\text { PDB } \\
\text { Code }\end{array}$ & Classification & Organisms & $\begin{array}{c}\text { Expression } \\
\text { System }\end{array}$ & Resolution & Method & $\begin{array}{c}\text { Structure } \\
\text { Weight }\end{array}$ & Chain \\
\hline $\begin{array}{c}\text { Spike } \\
\text { (S1) }\end{array}$ & $7 \mathrm{BZ5}$ & Viral protein & $\begin{array}{c}\text { SARS- } \\
\text { nCoV2 }\end{array}$ & $\begin{array}{c}\text { Homo } \\
\text { sapiens }\end{array}$ & $1.84 \AA$ & $\begin{array}{c}\text { X-RAY } \\
\text { Diffraction }\end{array}$ & $\begin{array}{c}73.36 \\
\mathrm{kDa}\end{array}$ & $\mathrm{A}$ \\
RdRP & 7BW4 & Replication & $\begin{array}{l}\text { SARS- } \\
\text { nCoV2 }\end{array}$ & $\begin{array}{c}\text { Escherichia } \\
\text { Coli }\end{array}$ & $3.70 \AA$ & $\begin{array}{c}\text { Electron } \\
\text { Microscopy }\end{array}$ & $\begin{array}{c}159.03 \\
\mathrm{kDa}\end{array}$ & $\mathrm{A}$ \\
\hline
\end{tabular}

\subsection{Docking process}

The interaction of our chosen ligands with the active sites of the 7BZ5 and 7BW4 was carried out by means of dock feature implanted in MOE, using its own built-in algorithms and tools. Additionally, the molecular interactions with the binding site of the receptors consumed some time to complete. The docking scores of the ligands displayed in a tabulated form in a new window after completion. Together with, ligands 2D and 3D interactions were also visible by choosing their options as well. These interactions showed that where the probable hydrogen bonds were formed with amino acids. Our main emphasis was on the binding energies or EScore of this docking process to consider Carica papaya compounds as a potent drug agents (Krovat et al., 2005).

Figure 2 Proteins used for docking studies: (a) Spike; 7BZ5 and (b) RdRP; 7BW4

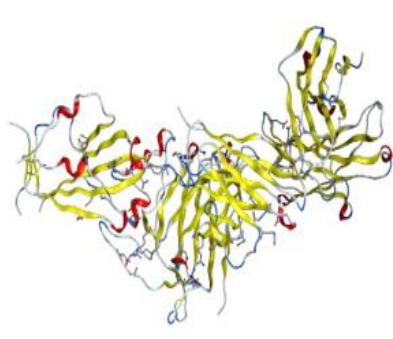

(a)

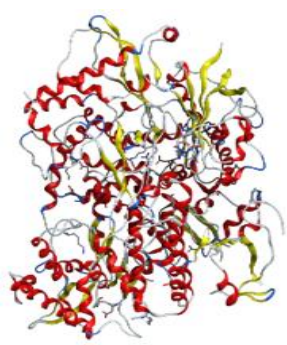

(b) 


\section{Results and discussions}

Our docking results revealed that some compounds of Carica papaya extracts have the lowest energies with different nature of proteins 7BZ5 and 7BW4 respectively. Here we deliberated the ligands properties and their docking scores. Moreover, the medicinal significance, ligand-protein interactions and surface maps of major compounds (having best docking scores) were also described one by one in detail.

\subsection{Ligands and their lipinski's physiochemical properties rule}

Initially, we confer about the ligands, which we selected and prepared for our docking purposes. Chemical structures, their general names, PubChem ID's and molecular formulas of chemical compounds from Carica papaya are reported in Table 2. Additionally, Lipinski's rule key physiochemical parameters were also studied for each ligand (testified in Table 2) along with the violations of this rule by using SwissADME web tool to evaluate drug likeliness attributes (http://www.swissadme.ch/index.php). There are total 12 derived compounds of papaya, which were studied and observed. Out of which 4 compounds (Papain, $\beta$-Cryptoxanthin, Lycopene and Lutein) violate the Lipinski's rule with 2 violations each. Rest of the ligands have zero violations and fulfil the properties of this rule. So, all these ligands are acknowledged according to Lipinski's rule of 5 and could be considered as potential inhibitors (Benet et al., 2016). Many studies also suggested that Lipinski's physiochemical rules are not applicable on natural as well as on artificial drugs (Zhang and Wilkinson, 2007).

Table 2 Chemical structure of derived substances from Carica papaya with Lipinski's rule

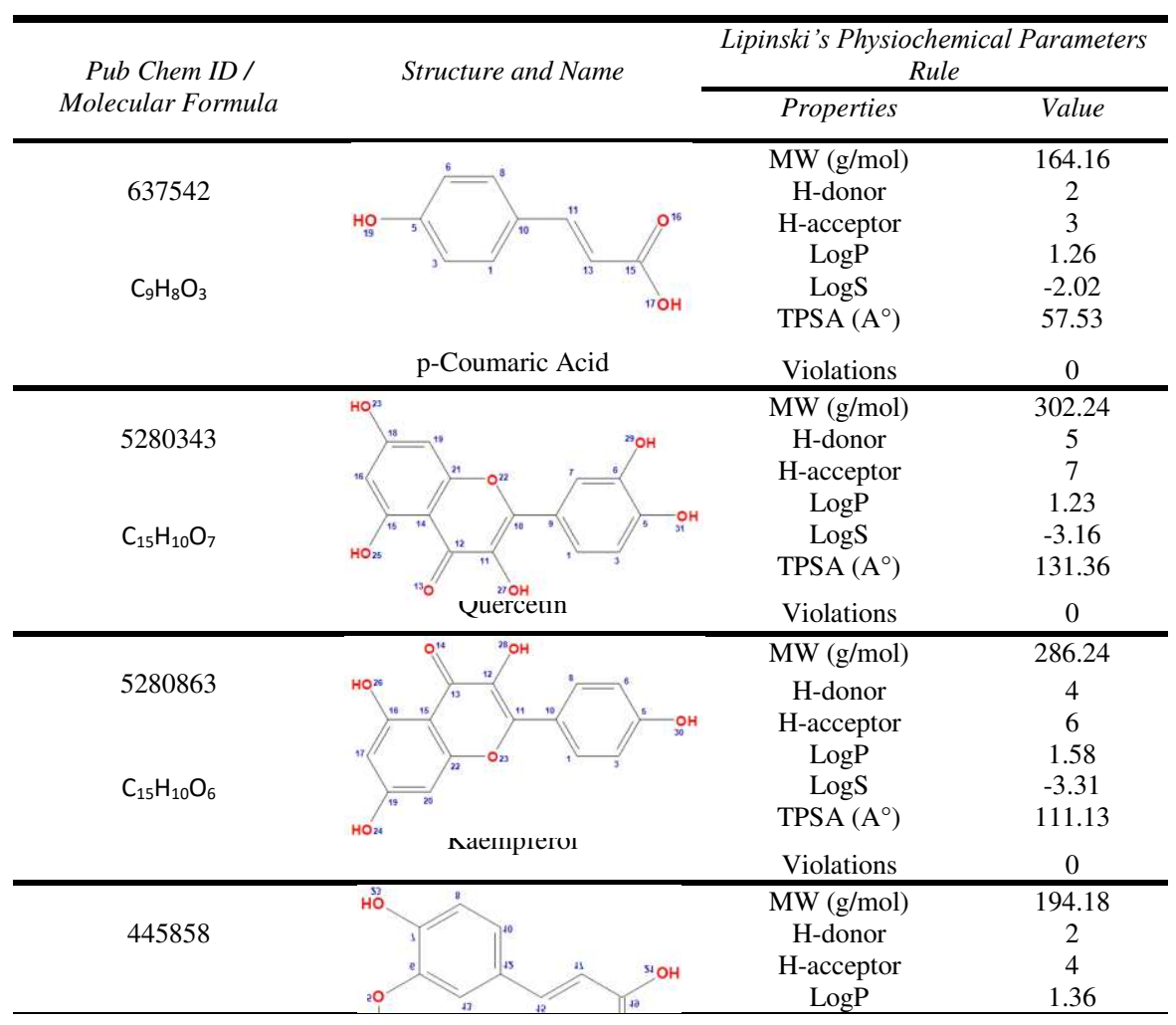




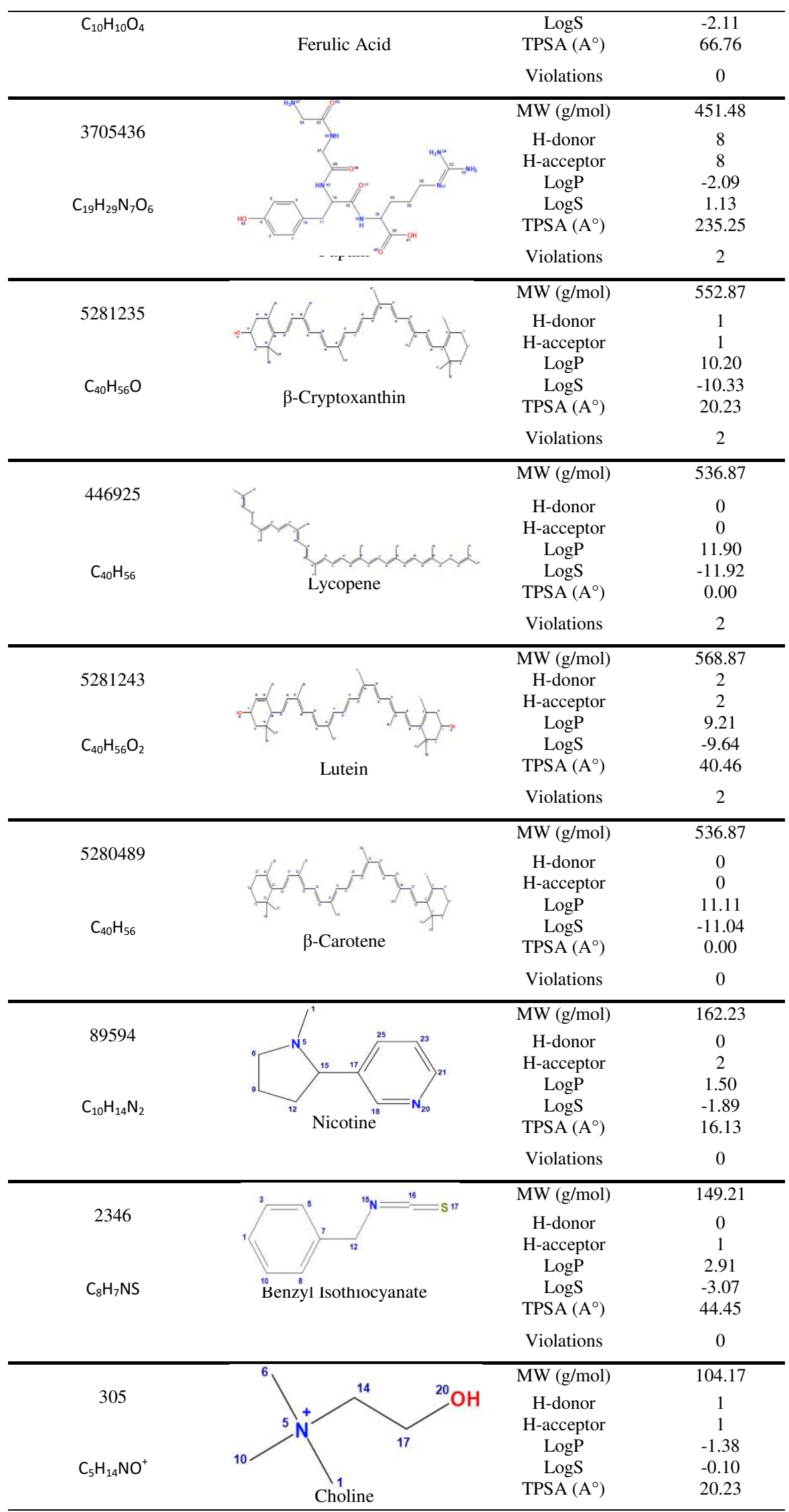




\subsection{Docking scores}

Table 3 reports E-score $(\mathrm{Kcal} / \mathrm{mol})$ or binding energies obtained from docking of Carica papaya compounds with 7BZ5 and 7BW4. Acquired results showed that Lutein gave the lowest binding energy i.e. $-8.9013 \mathrm{Kcal} / \mathrm{mol}$ in complex with 7BZ5 (Spike protein), which is the best score in our research compared to other docked compounds. In addition, Lycopene gave the lowest energy i.e. $-8.7148 \mathrm{Kcal} / \mathrm{mol}$ in complex with our second selected protein 7BW4 (RNADependent RNA polymerase), which is another best score among all docked compounds. These scores are the reckoning-based analysis in search for scheming the drugs against COVID-19.

Table 3 Docking results of Carica papaya compounds with 7BZ5 and 7BW4

\begin{tabular}{ccc}
\hline \multirow{2}{*}{ Ligands } & \multicolumn{2}{c}{ Scores $($ Kcal/mol $)$} \\
\cline { 2 - 3 } & 7 BZ5 & 7 BW4 \\
\hline p-Coumaric Acid & -4.8987 & -4.3025 \\
Quercetin & -6.3272 & -5.5544 \\
Kaempferol & -5.4416 & -5.5174 \\
Ferulic Acid & -5.0683 & -5.0404 \\
Papain & -8.6222 & -7.9099 \\
$\beta$-Cryptoxanthin & -8.6993 & -8.5152 \\
Lycopene & -8.3588 & -8.7148 \\
Lutein & -8.9013 & -8.4875 \\
$\beta$-Carotene & -8.7844 & -8.1668 \\
Nicotine & -4.9437 & -5.0314 \\
Benzyl Isothiocyanate & -4.6074 & -4.4378 \\
Choline & -4.2034 & -4.2146 \\
\hline
\end{tabular}

\subsection{Medicinal significance of ligands}

The major compounds which gave the best docking score and lower energies were meant to be the therapeutic drugs used against the causative agent (SARS-nCoV2). There medicinal significance were studied and described as followed: the first major compound is Papain having properties like immunomodulatory, anti-oxidant and used for the treatment of inflammation (Mamboya, 2012). It has enzymatic activities which act as inhibitor as well. The second major compound having good docking score is $\beta$-Cryptoxanthin which belongs to carotenoids family. (https://www.phytochemicals.info/phytochemicals/beta-cryptoxanthin.php) The antioxidant property of this compound prevents cells and its machinery from making free radicals which otherwise can damage the cells and tissues (Burri et al., 2016). The third major compound which has maximum docking score with RdRP protein (7BW4) of $-8.7148 \mathrm{Kcal} / \mathrm{mol}$ is Lycopene. It is a naturally occurring carotenoid which is a powerful antioxidant molecule that scavenges ROS; reactive oxygen species (Story et al., 2010). It has a potential health benefits in many biological activities in humans. It also uncovered a critical antiviral impact and anticytotoxic movement against HSV-1 contamination. The fourth major compound is Lutein which gave the maximum docking score with Spike protein (7BZ5) of $-8.9013 \mathrm{Kcal} / \mathrm{mol}$. It is rich in anti-oxidants, which 
plays an anti- inflammatory role as per literature studies (Buscemi et al., 2018). It also protects cells against the harmful effects of free radicals. In the preceding, the fifth major compound is $\beta$ Carotene which is a strong antioxidant, human metabolite having chemopreventive activities. It stimulates immune system by the release of killer cells, lymphocytes and phagocytes (Lustgarten et al., 2011). All these ligands have scientifically impactful against the damage caused by the foreign agents of viral infection and acts as the immunomodulator in cellular events.

\subsection{Interactions of ligands with 7 BZ5 complex}

By using MOE software, we got the results of all possible ligand-protein interactions after the completion of docking process. All the observable interactions of 7BZ5 complex with the major compounds of Carica papaya having the lower binding energies are discussed in table 4. Firstly, the ligand interactions with the active site of spike protein (7BZ5) can be easily observed. Secondly, the probable hydrogen interactions with the amino acids, type of bonding, their required energies (in Kcal/mol) and their distances in Angstrom $(\AA)$ are mentioned. Thirdly, the surface maps are graphically represented with the attachment sites of ligands in Spike protein. Besides, there are some compounds which have the best docking scores with non-perceptible hydrogen interactions.

Table 4 2D and 3D interactions of the major compounds from Carica papaya with 7BZ5

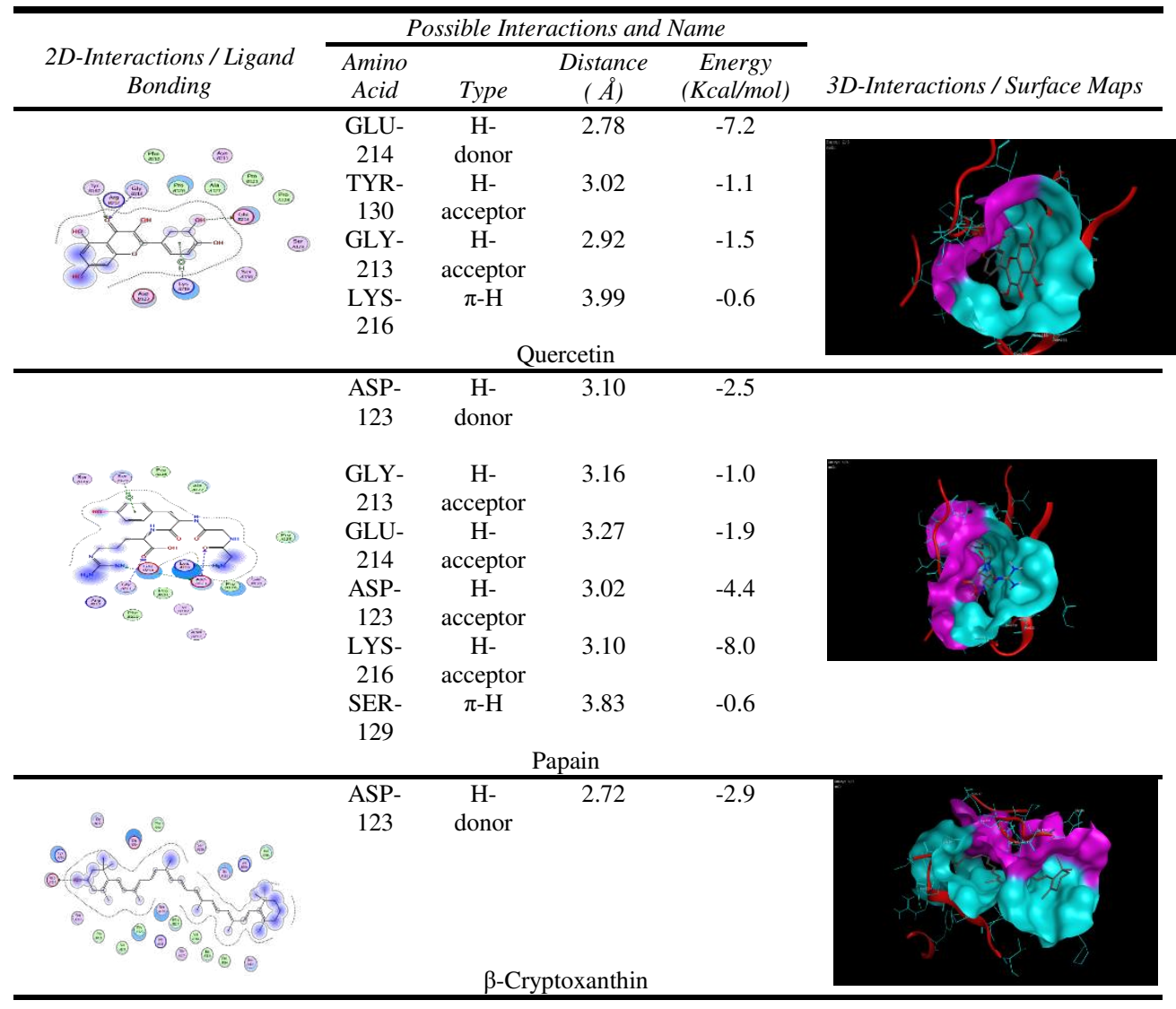




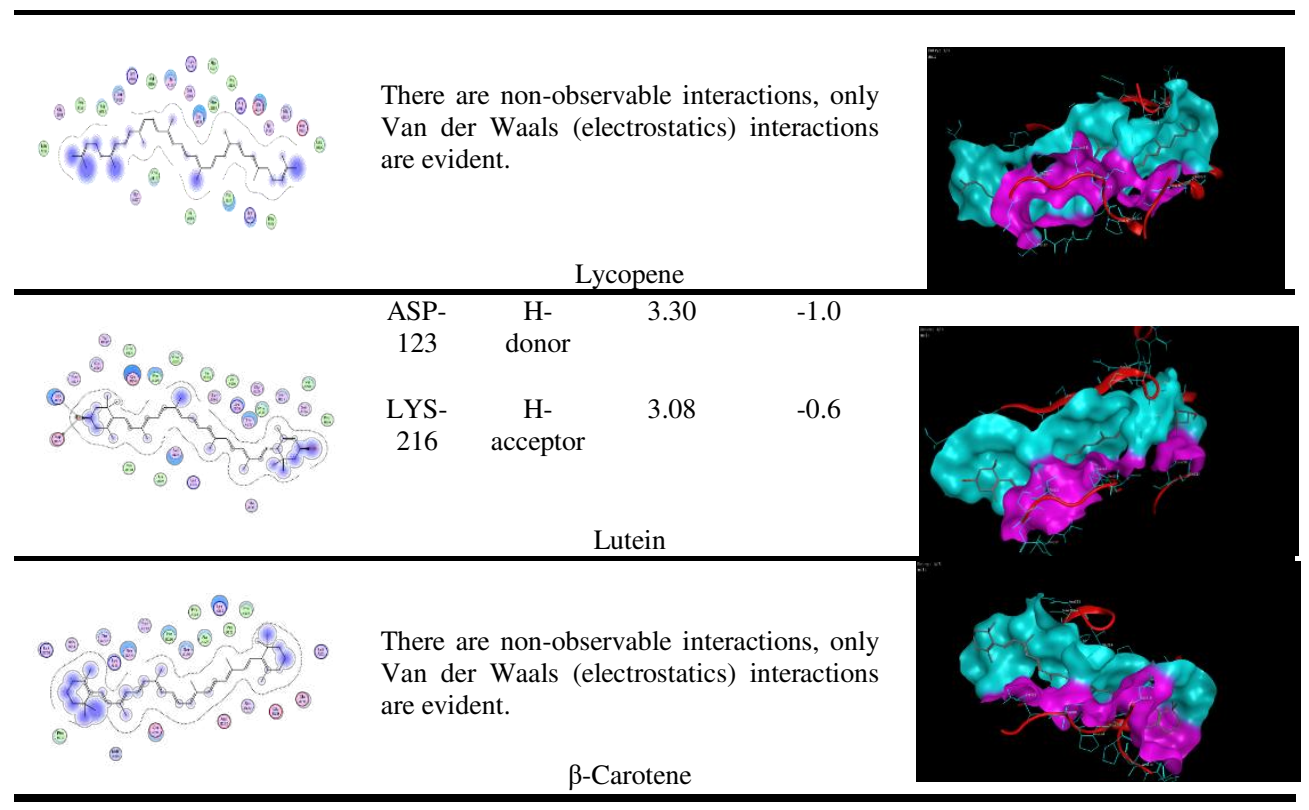

\subsection{Interactions of ligands with 7BW4 enzyme}

After the completion of docking process, we got the results of all possible ligand-protein interactions of major compounds of Carica papaya (having the best docking scores) with 7BW4 as shown in table 5. Primarily, the 2D-interactions of ligands with the active sites of (7BW4) RNA-dependent RNA polymerase (RdRP) is displayed. Furthermore, the noticeable hydrogen interactions with the amino acids, type of bonding, their distances in Angstrom $(\AA)$, binding energies $(\mathrm{Kcal} / \mathrm{mol})$ and 3D-interactions are mentioned. Moreover, there are two compounds (Lycopene and $\beta$-Carotene) which have non-perceptible hydrogen interactions as well.

Table 5 2D and 3D interactions of the major compounds of Carica papaya with 7BW4

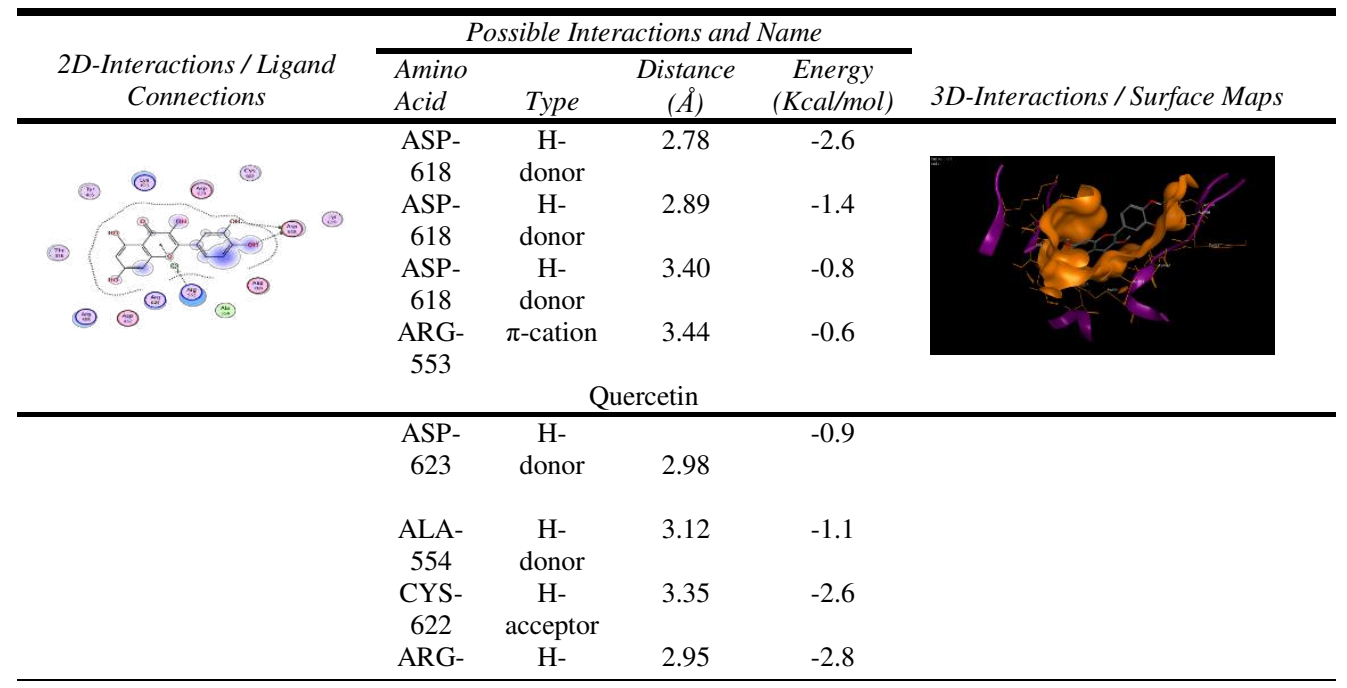




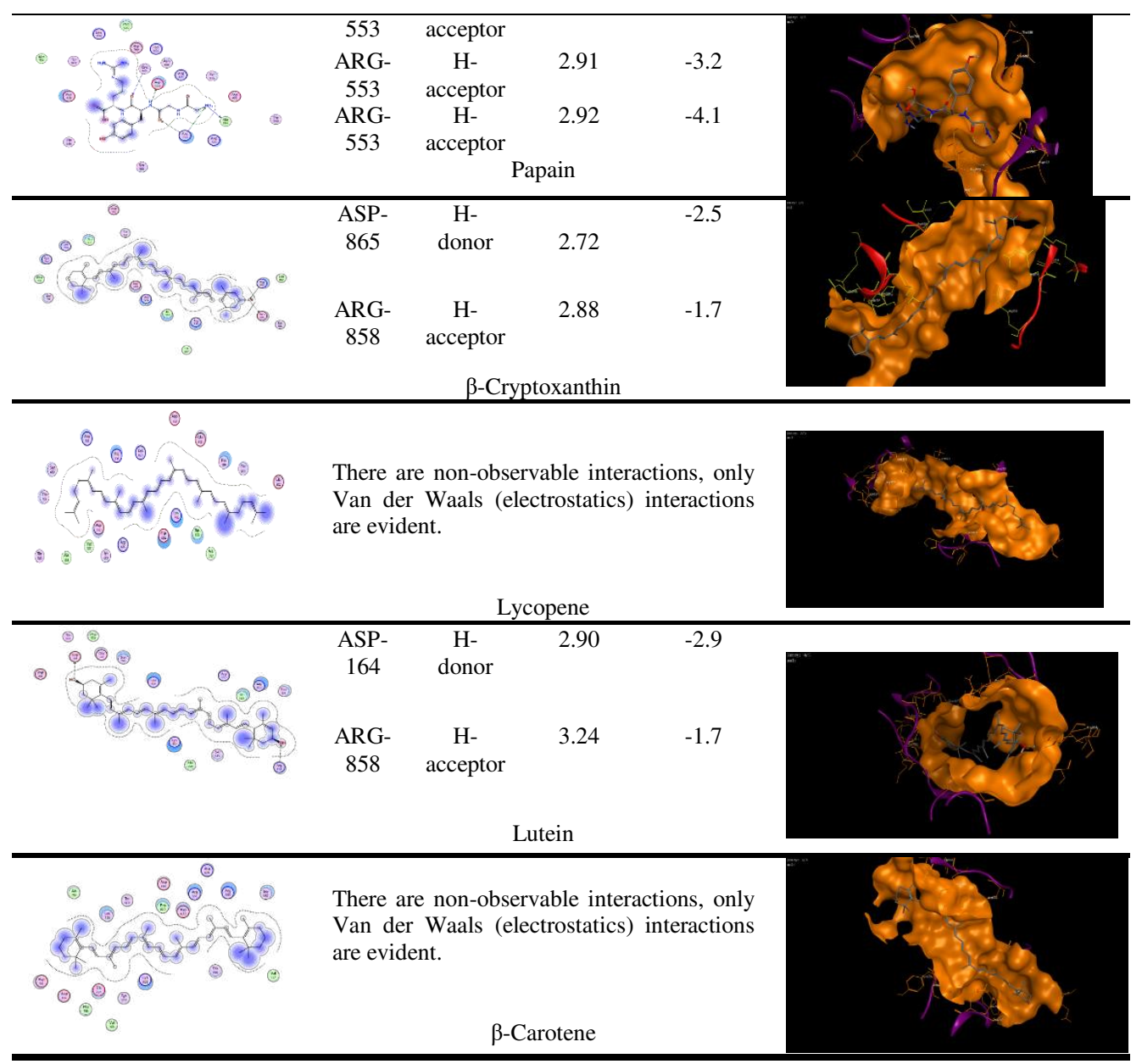

\section{Conclusion}

By and large, the current study has provided insights into computational prophecy about the drug agents from Carica papaya compounds which may be beneficial against SARS-nCoV2. The two main targets of viral proteins (Spike, RdRP) are tested and predicted as evident agents because of their molecular binding and docking score with the selected ligands. Therefore, the major compounds from Carica papaya (includes: Papain, $\beta$-Cryptoxanthin, Lycopene, Lutein and $\beta$ Carotene) have more potential to inhibit COVID-19 as compared to other drugs used at present for the treatment of this disease. Moreover, these compounds have immunomodulatory significance and ability to fight against the inflammation caused by this virus. Consequently, these results encourage further in vivo and in vitro investigations to be used as drug against SARS-nCoV2 preveniently. 


\section{References}

Ahmed, S. F., Quadeer, A. A. \& Mckay, M. R. 2020. Preliminary Identification Of Potential Vaccine Targets For The Covid-19 Coronavirus (Sars-Cov-2) Based On Sars-Cov Immunological Studies. Viruses, 12, 254.

Benet, L. Z., Hosey, C. M., Ursu, O. \& Oprea, T. I. 2016. Bddcs, The Rule Of 5 And Drugability. Advanced Drug Delivery Reviews, 101, 89-98.

Bouchentouf, S. \& Missoum, N. 2020. Identification Of Compounds From Nigella Sativa As New Potential Inhibitors Of 2019 Novel Coronasvirus (Covid-19): Molecular Docking Study.

Burri, B. J., La Frano, M. R. \& Zhu, C. 2016. Absorption, Metabolism, And Functions Of BCryptoxanthin. Nutrition Reviews, 74, 69-82.

Buscemi, S., Corleo, D., Di Pace, F., Petroni, M. L., Satriano, A. \& Marchesini, G. 2018. The Effect Of Lutein On Eye And Extra-Eye Health. Nutrients, 10, 1321.

Cucinotta, D. \& Vanelli, M. 2020. Who Declares Covid-19 A Pandemic. Acta Bio-Medica: Atenei Parmensis, 91, 157-160.

Dar, A. M. \& Mir, S. 2017. Molecular Docking: Approaches, Types, Applications And Basic Challenges. J Anal Bioanal Tech, 8, 1-3.

Dhama, K., Sharun, K., Tiwari, R., Dadar, M., Malik, Y. S., Singh, K. P. \& Chaicumpa, W. 2020. Covid-19, An Emerging Coronavirus Infection: Advances And Prospects In Designing And Developing Vaccines, Immunotherapeutics, And Therapeutics. Human Vaccines \& Immunotherapeutics, 1-7.

Goswami, D., Kumar, M., Ghosh, S. K. \& Das, A. 2020. Natural Product Compounds In Alpinia Officinarum And Ginger Are Potent Sars-Cov-2 Papain-Like Protease Inhibitors.

Hall Jr, D. C. \& Ji, H.-F. 2020. A Search For Medications To Treat Covid-19 Via In Silico Molecular Docking Models Of The Sars-Cov-2 Spike Glycoprotein And 3cl Protease. Travel Medicine And Infectious Disease, 101646.

Khaerunnisa, S., Kurniawan, H., Awaluddin, R., Suhartati, S. \& Soetjipto, S. 2020. Potential Inhibitor Of Covid-19 Main Protease (Mpro) From Several Medicinal Plant Compounds By Molecular Docking Study. Prepr. Doil0, 20944, 1-14.

Khalid, Z., Yousaf, M. A., Khan, A. T.-A., Shakoori, F. R., Munir, M. \& Shakoori, A. R. 2020. Debunking Myths About Covid-19, Paranoiac Misconceptions, Recent Developments And Its Current Stance. Pak. J. Zool, 52.

Khan, A., Khan, M., Saleem, S., Babar, Z., Ali, A., Khan, A. A., Sardar, Z., Hamayun, F., Ali, S. S. \& Wei, D.-Q. 2020. Phylogenetic Analysis And Structural Perspectives Of RnaDependent Rna-Polymerase Inhibition From Sars-Cov-2 With Natural Products. Interdisciplinary Sciences: Computational Life Sciences, 12, 335-348.

Kronbichler, A., Effenberger, M., Eisenhut, M., Lee, K. H. \& Shin, J. I. 2020. Seven Recommendations To Rescue The Patients And Reduce The Mortality From Covid-19 Infection: An Immunological Point Of View. Autoimmunity Reviews, 102570.

Krovat, E., Steindl, T. \& Langer, T. 2005. Recent Advances In Docking And Scoring. Current Computer-Aided Drug Design, 1, 93-102.

Li, W., Moore, M. J., Vasilieva, N., Sui, J., Wong, S. K., Berne, M. A., Somasundaran, M., Sullivan, J. L., Luzuriaga, K. \& Greenough, T. C. 2003. Angiotensin-Converting Enzyme 2 Is A Functional Receptor For The Sars Coronavirus. Nature, 426, 450-454.

Lustgarten, M., Muller, F. L. \& Van Remmen, H. 2011. An Objective Appraisal Of The Free Radical Theory Of Aging. Handbook Of The Biology Of Aging. Elsevier. 
Mamboya, E. A. F. 2012. Papain, A Plant Enzyme Of Biological Importance: A Review. American Journal Of Biochemistry And Biotechnology, 8, 99-104.

Mirza, M. U. \& Froeyen, M. 2020. Structural Elucidation Of Sars-Cov-2 Vital Proteins: Computational Methods Reveal Potential Drug Candidates Against Main Protease, Nsp12 Polymerase And Nsp13 Helicase. Journal Of Pharmaceutical Analysis.

Pal, M., Berhanu, G., Desalegn, C. \& Kandi, V. 2020. Severe Acute Respiratory Syndrome Coronavirus-2 (Sars-Cov-2): An Update. Cureus, 12.

Pandey, S., Cabot, P. J., Shaw, P. N. \& Hewavitharana, A. K. 2016. Anti-Inflammatory And Immunomodulatory Properties Of Carica Papaya. Journal Of Immunotoxicology, 13, 590602.

Peng, Q., Peng, R., Yuan, B., Zhao, J., Wang, M., Wang, X., Wang, Q., Sun, Y., Fan, Z. \& Qi, J. 2020. Structural And Biochemical Characterization Of Nsp12-Nsp7-Nsp8 Core Polymerase Complex From Sars-Cov-2. Cell Reports, 107774.

Prasanna, P. L. \& Abilash, V. 2020. Coronaviruses Pathogenesis, Comorbidities And MultiOrgan Damage-A Review. Life Sciences, 117839.

Rivera-Pastrana, D., Yahia, E. \& González-Aguilar, G. 2010. Identification Of Phenolic And Carotenoid Compounds In Carica Papaya L.'Maradol'using Liquid ChromatographyMass Spectrometry. Acta Horticulturae, 877, 1197-1204.

Salvatori, G., Luberto, L., Maffei, M., Aurisicchio, L., Roscilli, G., Palombo, F. \& Marra, E. 2020. Sars-Cov-2 Spike Protein: An Optimal Immunological Target For Vaccines. Journal Of Translational Medicine, 18, 1-3.

Santiago, V., Giorgio, C. \& Stefano, M. 2008. Medicinal Chemistry And The Molecular Operating Environment (Moe): Application Of Qsar And Molecular Docking To Drug Discovery. Current Topics In Medicinal Chemistry, 8, 1555-1572.

Story, E. N., Kopec, R. E., Schwartz, S. J. \& Harris, G. K. 2010. An Update On The Health Effects Of Tomato Lycopene. Annual Review Of Food Science And Technology, 1, 189210.

Wang, T., Du, Z., Zhu, F., Cao, Z., An, Y., Gao, Y. \& Jiang, B. 2020. Comorbidities And MultiOrgan Injuries In The Treatment Of Covid-19. The Lancet, 395, E52.

Wrobel, A. G., Benton, D. J., Xu, P., Roustan, C., Martin, S. R., Rosenthal, P. B., Skehel, J. J. \& Gamblin, S. J. 2020. Sars-Cov-2 And Bat Ratg13 Spike Glycoprotein Structures Inform On Virus Evolution And Furin-Cleavage Effects. Nature Structural \& Molecular Biology, 27, 763-767.

Wu, Y., Wang, F., Shen, C., Peng, W., Li, D., Zhao, C., Li, Z., Li, S., Bi, Y. \& Yang, Y. 2020. A Noncompeting Pair Of Human Neutralizing Antibodies Block Covid-19 Virus Binding To Its Receptor Ace2. Science, 368, 1274-1278.

Zhang, D.-H., Wu, K.-L., Zhang, X., Deng, S.-Q. \& Peng, B. 2020. In Silico Screening Of Chinese Herbal Medicines With The Potential To Directly Inhibit 2019 Novel Coronavirus. Journal Of Integrative Medicine, 18, 152-158.

Zhang, M.-Q. \& Wilkinson, B. 2007. Drug Discovery Beyond The 'Rule-Of-Five'. Current Opinion In Biotechnology, 18, 478-488.

Zou, L., Ruan, F., Huang, M., Liang, L., Huang, H., Hong, Z., Yu, J., Kang, M., Song, Y. \& Xia, J. 2020. Sars-Cov-2 Viral Load In Upper Respiratory Specimens Of Infected Patients. New England Journal Of Medicine, 382, 1177-1179. 
Figures

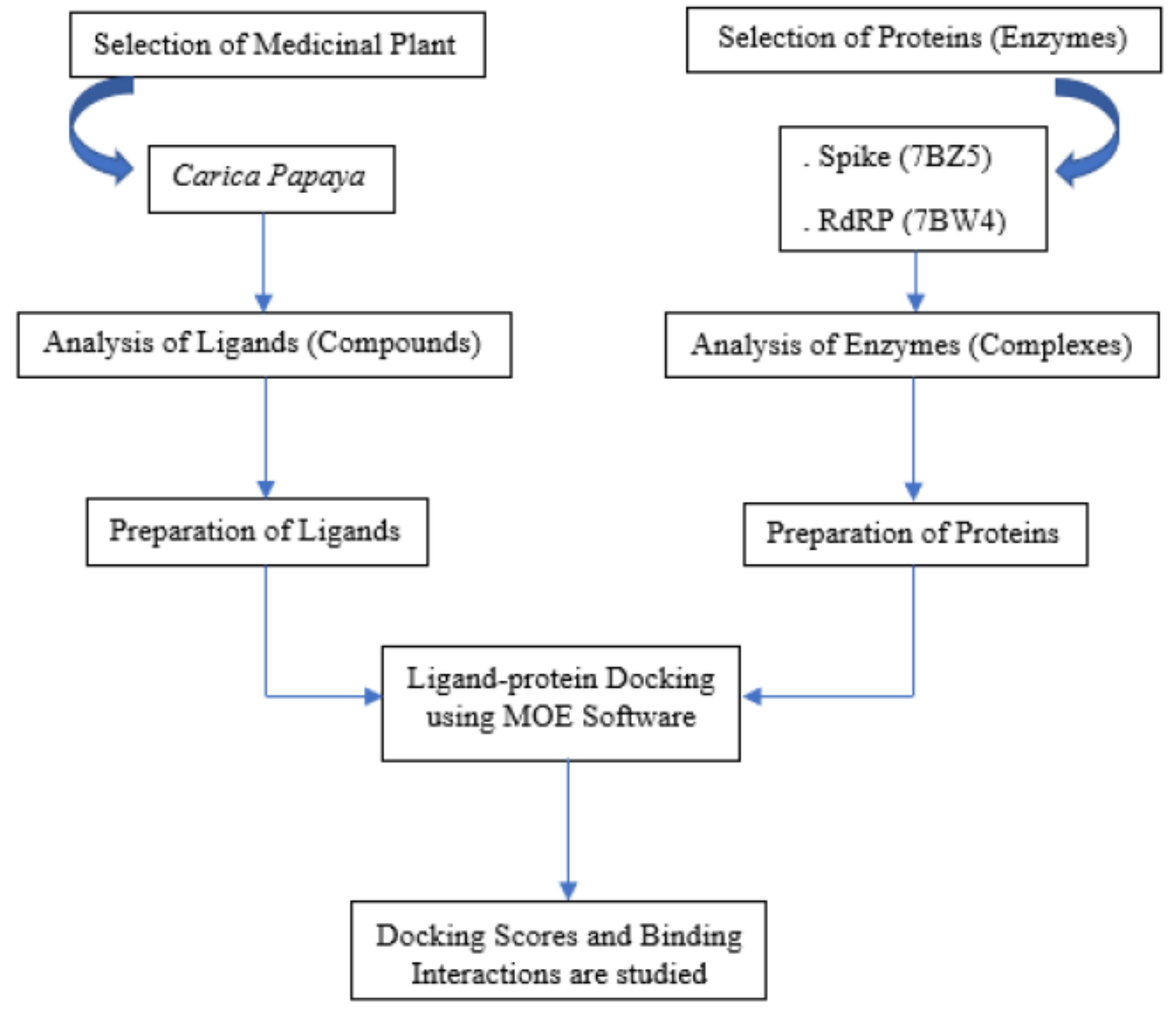

Figure 1

Comprehensive work stream of docking study 


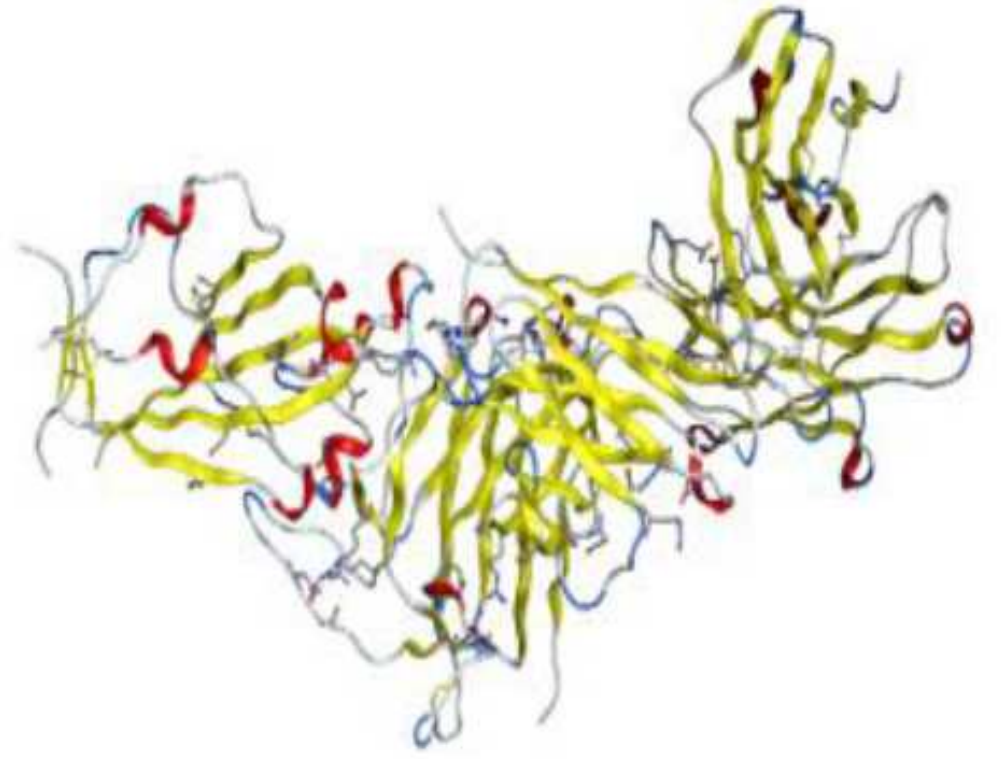

(a)

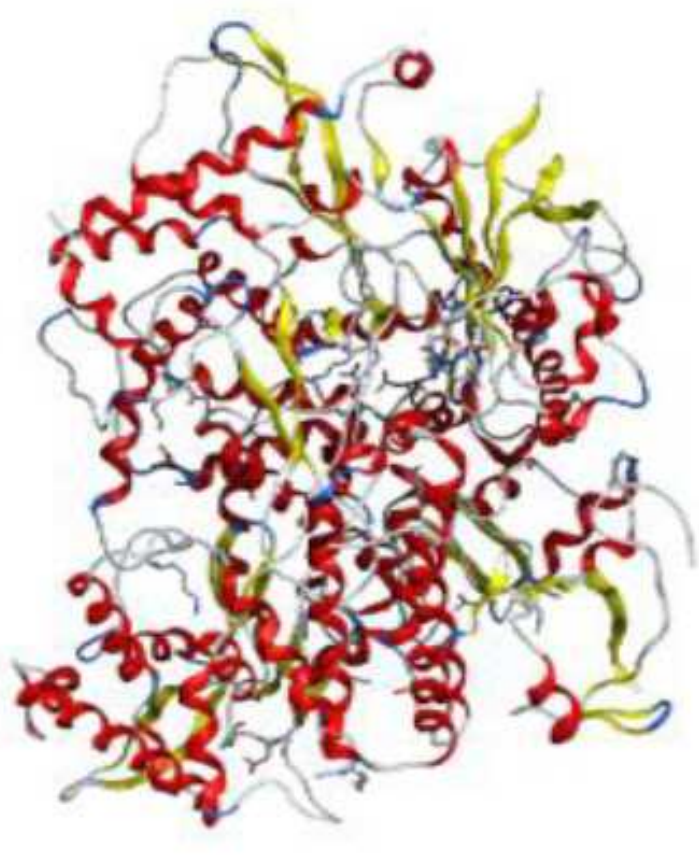

(b)

Figure 2

Proteins used for docking studies: (a) Spike; 7BZ5 and (b) RdRP; 7BW4 